\title{
RESEARCH
}

Open Access

\section{Fungal and parasitic contamination of indoor public swimming pools in Arak, Iran}

Hossein Sarmadian ${ }^{1}$, Yasamin Hazbavi², Mojtaba Didehdar², Mohammad Javad Ghannadzadeh³, Reza Hajihossein², Mahmood Khosravi ${ }^{4}$ and Reza Ghasemikhah ${ }^{2 *}$ (i)

\begin{abstract}
Background: Swimming is a popular exercise for different types of people at different ages. Public swimming pools are places where fungal infections can be easily transferred. The purpose of this study is to evaluate the quality of mycological, parasitological, and physicochemical parameters of swimming pools of Arak city.

Methods: This cross-sectional study was done for 12 months from April 2013 to March 2014 in six indoor active swimming pools of Arak city (A, B, C, D, E, and F). Samples were collected in four seasons, two times/season; each time, two samples were obtained from six specified locations (shallow level pool, deep level pool, dressing rooms, showers, margin of pool walls, and foot-washing sink) from each pool with a total of 576 samples. Physicochemical parameters including water temperature, $\mathrm{pH}$, turbidity, and the residual chlorine were measured on-site. In order to isolate and detect the fungal agents, special filters and culture Sabouraud's dextrose agar, chloramphenicol, and mycosel agar media were applied. Furthermore, non-nutrient agar medium enriched with Escherichia coli was used to detect and to separate the eggs of the worms, cysts, and parasitic protozoa from centrifuges of samples. In order to investigate their sediment, optical microscope and culture media were used.
\end{abstract}

Results: We found that 456 (79.1\%) samples were positive regarding the fungal elements, and 516 fungal species were isolated. The most common isolates were saprophytic species (8.74\%), yeast species (25\%), and dermatophyte species (2.5\%). The most contaminated surfaces were foot-washing sinks and showers. In this study, Acanthamoeba parasites were isolated from one pool only.

All the investigated physicochemical parameters of pool water except for the temperature were found to be in the standard range.

Conclusions: Existence of saprophytic fungi and yeast in pools' water is plausible to be considered as an indicator of water resistance to the detergent agents. This high degree of contamination is due to the huge number of visitors, the complexity of construction, the choice of materials, and the long opening hours. Isolation of dermatophytes and Acanthamoeba parasite from the pools' area and foot-washing sink reveals the important role of the public swimming pools in disease transmission.

Keywords: Acanthamoeba, Arak, Fungi, Physicochemical parameters, Public swimming pools

\footnotetext{
*Correspondence: ghasemikhah@gmail.com; ghasemikhah@yahoo.com

${ }^{2}$ Department of Parasitology and Mycology, Arak University of Medical

Sciences, Arak, Iran

Full list of author information is available at the end of the article
} 


\section{Introduction}

Swimming is an excellent way to get the physical activity and health benefits needed for having a healthy life at all ages. However, the cleanliness of the water and its management should be guaranteed [1]. Swimming pools are usually accompanied with potentially hazardous health issues. Indeed, given that they are being used by many people within a restricted time period, they are a suitable place for transferring infections and skin diseases. Poolborne communicable diseases include bacterial infections such as eye infections, external otitis, parasitic diseases such as giardiasis and cryptosporidiosis, and fungal diseases such as dermatophytosis and opportunistic mycosis [2-6]. Therefore, swimming pool pollution has become a growing concern.

These fungi are causing a spectrum of infections including dermatophytosis [7]. If someone with this infection goes to a swimming pool, he has a direct role in transferring diseases and infections to others [8]. $\mathrm{Hu}$ midity, heat, and excessive heating can also be responsible for the transfer of fungal skin diseases. Hence, taking a shower before and after swimming and using a personal swimming cap, towel, and slippers are necessary, and those should not be shared with others. Those who are infected with dermatophytosis should not go swimming given that direct contact is another way of transferring diseases.

Evidence-based data show that swimming pools are suitable places for the growth of pathogenic fungi if they are not controlled or examined $[4,9]$. Surfaces of pool bottoms and edges, locker rooms, and showers are also suitable for the growth of dermatophyte fungi; other at-risk places include hot tubs given that saprophytic fungi can easily grow due to the humidity of the environment [10-12]. Opportunistic fungi have pathogenic potential for immunodeficient and immunocompromised subjects [10].

Acanthamoeba is a free-living opportunistic amoeba that has a global spread and is widely distributed in water, soil, air, sewage, and other environments [13]. Acanthamoeba species are observed in two forms of trophozoite and cysts. Acanthamoeba cyst is resistant to the chlorination and disinfection of water systems. The habitat of Acanthamoeba is water and especially pool water $[13,14]$. This amoeba can cause Acanthamoeba keratitis and central nervous system infection. There have been reports of people with keratitis who had swimming experiences in the pools [15].

The assessment of physicochemical parameters of swimming pool waters such as $\mathrm{pH}$, temperature, and residual chlorine has crucial role in water quality and pathogenic microorganism control [16]. Standard ranges of physicochemical parameters for swimming pool waters are as follows: $\mathrm{pH}$ between 7.2 and 8, temperature between 29 and $25^{\circ} \mathrm{C}$, and turbidity less than $0.5 \mathrm{NTU}$
(Nephelometric Turbidity Unit) and for residual chlorine 1-3 ppm (parts-per-million).

In alkaline $\mathrm{pH}$, less amount of the residual chlorine changes into hydrochloric acid and the disinfection effects became weaker $[1,17]$. Using materials other than chlorine as a disinfectant can lead to the transfer of different types of diseases in public places. Acidic $\mathrm{pH}$ of swimming pool water can lead to eye irritation and dry hair and skin and reduces the amount of residual chlorine [1].

Considering the importance of studying the fungal and parasitic contamination of swimming pools and the fact that no such study has been carried out in Arak city so far, therefore, the present study was performed to evaluate the fungal and Acanthamoeba contamination and physicochemical quality parameters in swimming pools in Arak city in the center of Iran.

\section{Methods}

\subsection{Study design, study setting, and sampling technique}

This cross-sectional study was done for 12 months from April 2013 to March 2014 in six indoor active swimming pools of Arak city (A, B, C, D, E, and F). Samples were collected in four seasons, two times/season; each time, two samples were obtained from six specified locations (shallow level pool, deep level pool, dressing rooms, showers, margin of pool walls, and foot-washing sink) from each pool with a total of 576 samples [18]. Sample from females' swimming pools were collected by a female sampler and from males' swimming pools by a male sampler.

Water samples were collected by using sterilized bottles from shallow and deep levels for physical and chemical parameters and mycological and parasitological analysis. In addition, four samples from dressing rooms, showers, margin of pool walls, and foot-washing sink were taken by using a piece of sterile carpet (size of $5 \times 5 \mathrm{~cm}^{2}$ ). The carpets were placed in sterile nylons. All samples were immediately transferred to the laboratory.

\subsection{Mycological investigations}

Samples of $100 \mathrm{ml}$ of collected water were passed through $45 \mu \mathrm{m}$ Millipore filters (Merck, Germany). Filters were put on Sabouraud's dextrose agar (SDA) with chloramphenicol and mycosel agar (Merck, Germany). Also, the carpets were shaken and put on Sabouraud's dextrose agar with chloramphenicol and mycosel agar. The media were incubated at $28^{\circ} \mathrm{C}$ for 3 weeks and investigated daily. Filamentous fungal isolates were identified by slide culture method [19]. Yeast fungal isolates were subcultured on CHROMagar ${ }^{\mathrm{TM}}$ Candida medium (CHROMagar, France) and incubated at $35^{\circ} \mathrm{C}$ for $48 \mathrm{~h}$. Discrimination of Candida species and other yeast species was done according to different colors produced by 
Candida colonies in the chromogenic medium according to the manufacturer's protocol [20].

\subsection{Parasitic investigations}

For isolation of Acanthamoeba parasite, $100 \mathrm{ml}$ of sampled waters was passed through $45 \mu \mathrm{m}$ size Millipore filters (Merck, Germany). Filters were put on a non-nutrient agar medium enriched with Escherichia coli [21]. Then, the lid of the medium plate was blocked with paraffin and incubated in a $28^{\circ} \mathrm{C}$ for 10 days. Afterwards, the plate was examined under a microscope with magnification of four times and ten times for Acanthamoeba colony.

For isolation of other parasites, $200 \mathrm{ml}$ of pool water was centrifuged at $4000 \mathrm{rpm}$ for $10 \mathrm{~min}$. Direct smear was prepared from precipitate and examined under a microscope with magnification of 10 times and 40 times for egg, cyst, and trophozoite of parasites.

\subsection{Physicochemical analysis}

Physicochemical parameters including water temperature, $\mathrm{pH}$, turbidity, and chlorine residual were measured on-site. Residual chlorine was determined with DPD (Plain test, USA) instrument, and $\mathrm{pH}$ was measured by general method. Water turbidity and temperature were determined using turbidimeters ( $\mathrm{HACH}$, USA) and a thermometer (HACH, USA) respectively.

\subsection{Statistical analysis}

SPSS version 13 was used for data analysis. Chi-squared test and one-way ANOVA were used. $p<0.05$ was considered the level of significance.

\section{Results}

\subsection{Percentage of fungal contamination and isolated fungi}

In this study, 456 (79.1\%) samples out of 576 collected samples were positive for fungal elements, and 516 fungal species were isolated. Our results indicate that the most common fungal isolates include 412 saprophytic fungi (79.8\%), 103 yeast species (20\%), and 1 dermatophyte species $(0.2 \%)$.

Table 1 shows that the most fungal contamination was observed in the swimming pools A and B and the least one in the pool E. The most common isolated fungal species were as follows: 103 Candida species (20\%), 86 Penicillium species (16.7\%), and 84 Aspergillus species (16.3\%). One case of the dermatophyte species which was isolated from foot-washing sink of the swimming pool C was Trichophyton rubrum (Tables 1 and 2). The most common species of the saprophytic fungi and yeast species that were isolated from the water of swimming pools include Aspergillus and Candida species (Table 2).

According to our findings, the most contaminated surfaces are foot-washing sinks and showers. The most

Table 1 Frequency of fungal species isolated regarding the type of swimming pool

\begin{tabular}{|c|c|c|c|c|c|c|c|c|}
\hline \multirow[t]{3}{*}{ Fungi species } & \multicolumn{7}{|c|}{ Type of pool } & \multirow[t]{3}{*}{$p$ value* } \\
\hline & $\bar{A}$ & $B$ & $C$ & $\mathrm{D}$ & $E$ & $F$ & Total & \\
\hline & №. (\%) & №. (\%) & No. (\%) & No. (\%) & No. (\%) & No. (\%) & No. (\%) & \\
\hline Candida spp. & $25(26)$ & $19(20)$ & $13(17)$ & $17(20)$ & $12(17)$ & $17(19)$ & $103(20)$ & $>0.05$ \\
\hline Candida albicans & $19(20)$ & $14(15)$ & $10(13)$ & $14(16)$ & $10(14)$ & $13(14)$ & $80(15.5)$ & $>0.05$ \\
\hline Candida parapsilosis & $5(5)$ & $4(4)$ & $2(3)$ & $3(3)$ & $2(3)$ & $4(4)$ & $20(4)$ & $>0.05$ \\
\hline Candida krusei & $1(1)$ & $1(1)$ & $1(1)$ & 0 & 0 & - & $3(0.5)$ & $>0.05$ \\
\hline Penicillium spp. & $16(17)$ & $18(19)$ & $11(15)$ & $16(19)$ & $12(17)$ & $13(14)$ & $86(16.7)$ & $>0.05$ \\
\hline Aspergillus spp. & $15(16)$ & $17(18)$ & $10(13)$ & $14(16)$ & $14(19)$ & $14(15)$ & $84(16.3)$ & $>0.05$ \\
\hline Alternaria spp. & $9(9)$ & $14(15)$ & $13(17)$ & $8(9)$ & $10(14)$ & $14(15)$ & $68(13.2)$ & $>0.05$ \\
\hline Fusarium spp. & $10(10)$ & $10(10)$ & $5(7)$ & $13(15)$ & $9(13)$ & $15(16)$ & $62(12)$ & $>0.05$ \\
\hline Cladosporium spp. & $4(4)$ & $5(5)$ & $9(12)$ & $5(6)$ & $6(8)$ & $9(10)$ & $38(7.3)$ & $>0.05$ \\
\hline Rhodotorula spp. & $5(5)$ & $5(5)$ & $5(7)$ & $3(3)$ & $4(6)$ & $4(4)$ & $26(5)$ & $>0.05$ \\
\hline Rhizopus spp. & $7(7)$ & $3(3)$ & $4(5)$ & $3(3)$ & $2(3)$ & $2(2)$ & $21(4)$ & $>0.05$ \\
\hline Mucor spp. & $3(3)$ & $3(3)$ & $3(4)$ & $6(7)$ & $1(1)$ & $2(2)$ & $18(3.5)$ & $>0.05$ \\
\hline Drechslera spp. & $1(1)$ & $1(1)$ & $1(1)$ & - & - & $1(1)$ & $4(0.8)$ & - \\
\hline Curvularia spp. & $1(1)$ & $1(1)$ & - & - & $1(1)$ & - & $3(0.6)$ & - \\
\hline Trichophyton rubrum & - & - & $1(1)$ & - & - & - & $1(0.2)$ & - \\
\hline Scopulariopsis spp. & - & - & - & $1(1)$ & - & - & $1(0.2)$ & - \\
\hline Acremonium spp. & - & - & - & - & $1(1)$ & - & $1(0.2)$ & - \\
\hline Total no. (\%) & 96 (18.6) & 96 (18.6) & 75 (14.5) & $86(16.7)$ & $72(14)$ & 91 (17.6) & $516(100)$ & $>0.05$ \\
\hline
\end{tabular}

*ANOVA

The mean difference is significant at the 0.05 level 
Table 2 Distribution and frequency of isolated fungi species according to place of sampling

\begin{tabular}{|c|c|c|c|c|c|c|c|}
\hline \multirow[t]{3}{*}{ Fungi species } & \multicolumn{6}{|c|}{ Place of sampling } & \multirow{3}{*}{$\begin{array}{l}p \\
\text { value* }^{*}\end{array}$} \\
\hline & Pool water & Foot-washing sink & Margin of pool walls & Shower & Dressing room & Total (\%) & \\
\hline & No. (\%) & №. (\%) & №. (\%) & No. (\%) & No. (\%) & No. (\%) & \\
\hline Candida spp. & $5(23)$ & $25(19)$ & $20(17)$ & $37(28)$ & $16(14)$ & $103(20)$ & $>0.05$ \\
\hline Candida albicans & $5(23)$ & $20(15)$ & $15(13)$ & $30(23)$ & $10(9)$ & $80(15.5)$ & $>0.05$ \\
\hline Candida parapsilosis & $0(0)$ & $5(4)$ & $4(3)$ & $6(5)$ & $5(5)$ & $20(4)$ & $>0.05$ \\
\hline Candida krusei & $0(0)$ & $0(0)$ & $1(1)$ & $1(1)$ & $1(1)$ & $3(0.5)$ & $>0.05$ \\
\hline Penicillium spp. & $0(0)$ & $20(15)$ & $20(17)$ & $17(13)$ & $29(26)$ & $86(16.7)$ & $>0.05$ \\
\hline Aspergillus spp. & $6(27)$ & $17(13)$ & $16(13)$ & $18(14)$ & $27(24)$ & $84(16.3)$ & $>0.05$ \\
\hline Alternaria spp. & $1(5)$ & $18(14)$ & $14(12)$ & $21(16)$ & $14(13)$ & $68(13.2)$ & $>0.05$ \\
\hline Fusarium spp. & $0(0)$ & $20(15)$ & $18(15)$ & $13(10)$ & $11(10)$ & $62(12)$ & $>0.05$ \\
\hline Cladosporium spp. & $3(14)$ & $10(8)$ & $15(13)$ & $2(2)$ & $8(7)$ & $38(7.3)$ & $>0.05$ \\
\hline Rodotorula spp. & $3(14)$ & $10(8)$ & $4(3)$ & $8(6)$ & $1(1)$ & $26(5)$ & $>0.05$ \\
\hline Rhizopus spp. & $2(9)$ & $5(4)$ & $3(3)$ & $9(7)$ & $2(2)$ & $21(4)$ & $>0.05$ \\
\hline Mucor spp. & $1(5)$ & $6(5)$ & $7(6)$ & $3(2)$ & $1(1)$ & $18(3.5)$ & $>0.05$ \\
\hline Drechslera spp. & $0(0)$ & $1(1)$ & $0(0)$ & $2(2)$ & $1(1)$ & $4(0.8)$ & $>0.05$ \\
\hline Curvularia spp. & $1(5)$ & $0(0)$ & $1(1)$ & $1(1)$ & - & $3(0.6)$ & - \\
\hline Trichophyton rubrum & $0(0)$ & $0(0)$ & $0(0)$ & $0(0)$ & - & $1(0.2)$ & - \\
\hline Scopulariopsis spp. & $0(0)$ & $0(0)$ & $1(1)$ & $0(0)$ & - & $1(0.2)$ & - \\
\hline Acremonium spp. & $0(0)$ & $0(0)$ & $0(0)$ & $0(0)$ & $1(1)$ & $1(0.2)$ & - \\
\hline Total (\%) & $22(4.3)$ & $133(25.5)$ & $119(23)$ & $131(25.4)$ & $111(21.5)$ & $516(100)$ & $>0.05$ \\
\hline
\end{tabular}

*ANOVA

The mean difference is significant at the 0.05 level

frequently isolated species from these places were Candida, Penicillium, and Aspergillus species (Table 2).

As it is demonstrated in (Table 3), the fungal contamination of the swimming pools was higher in the summer season than any other times. The most isolated fungal species in this season were Candida species, Penicillium species, Aspergillus species, and Fusarium species. Among the isolated Candida species, the most common species were $C$. albicans, C. parapsilosis, and C. krusei, respectively (Tables 1, 2 , and 3).

\subsection{Percentage of parasitic contamination}

Acanthamoeba parasite was detected in only one pool from the six studied pools; it was mainly detected in foot-washing sinks, surface water, and deep water.

\subsection{Sanitary parameters}

Physical and chemical parameters were in standard range except for the temperature parameter (Table 4); among the studied swimming pools, the highest and the lowest $\mathrm{pH}$ levels were in pools A and C (Table 4). Residual chlorine in the winter and summer was high, and swimming pools had higher levels of turbidity in the summer than in other seasons (Table 4).

\section{Discussion}

Swimming pools are suitable places for transferring the pathogenic and potentially pathogenic microorganisms to human [22]. Factors such as swimmers' skin infections along with the lack of $\mathrm{pH}$ control and inadequate disinfection of swimming pools have an important role in transferring infectious diseases [16].

In the present study, physiochemical parameters of swimming pools, water fungal contamination, and pools' surroundings in Arak were investigated. Results showed that fungi species were found in $79.1 \%$ of swimming pools' water or surface samples. These species were saprophytic fungi $(74.8 \%)$, yeast species $(25 \%)$, and dermatophytes species $(0.2 \%)$.

Several studies in different parts of Iran and the world were done to investigate pool contamination [4, $8,9,11,16,17,23-27]$. Similarly to other studies in Iran, we found that saprophytic filamentous fungi were the most prevalent $[11,17,23,24]$ and Candida species were the most common fungal isolate. Similar to Rasti in Kashan and Jahanbakhsh, in Urmia, we found that fungal contamination was more common during the summer season, and the least problematic in the spring due to the fact that pools have more swimmers in summer and the heat and humidity are higher in this season [17]. 
Table 3 Distribution of isolated fungi species according to season

\begin{tabular}{|c|c|c|c|c|c|c|}
\hline \multirow[t]{3}{*}{ Fungal species } & \multicolumn{5}{|l|}{ Season } & \multirow[t]{3}{*}{$p$ value* } \\
\hline & Spring & Summer & Fall & Winter & Total (\%) & \\
\hline & №. (\%) & №. (\%) & No. (\%) & No. (\%) & №. (\%) & \\
\hline Candida spp. & $17(15)$ & $45(26)$ & $22(18)$ & $19(18)$ & $103(20)$ & $>0.05$ \\
\hline Candida albicans & $15(13)$ & $37(22)$ & $15(12)$ & $13(12)$ & $80(15.5)$ & $>0.05$ \\
\hline Candida parapsilosis & $1(1)$ & $8(5)$ & $5(4)$ & $6(6)$ & $20(4)$ & $>0.05$ \\
\hline Candida krusei & $1(1)$ & $0(0)$ & $2(2)$ & $0(0)$ & $3(0.5)$ & $>0.05$ \\
\hline Penicillium spp. & $18(16)$ & $25(15)$ & $23(19)$ & $20(19)$ & $86(17)$ & $>0.05$ \\
\hline Aspergillus spp. & $21(18)$ & $25(15)$ & $22(18)$ & $16(15)$ & $84(16)$ & $>0.05$ \\
\hline Alternaria spp. & $17(15)$ & $16(9)$ & $20(16)$ & $15(14)$ & $68(13)$ & $>0.05$ \\
\hline Fusarium spp. & $15(13)$ & $22(13)$ & $10(8)$ & $15(14)$ & $62(12)$ & $>0.05$ \\
\hline Cladosporium spp. & $6(5)$ & $12(7)$ & $15(12)$ & $5(5)$ & $38(7)$ & $>0.05$ \\
\hline Rodotorula spp. & $5(4)$ & $9(5)$ & $7(6)$ & $5(5)$ & $26(5)$ & $>0.05$ \\
\hline Rhizopus spp. & $12(10)$ & $4(2)$ & $0(0)$ & $5(5)$ & $21(4)$ & $>0.05$ \\
\hline Mucor spp. & $2(2)$ & $8(5)$ & $4(3)$ & $4(4)$ & $18(3.5)$ & $>0.05$ \\
\hline Drechslera spp. & $0(0)$ & $2(1)$ & $1(1)$ & $1(1)$ & $4(0.8)$ & - \\
\hline Curvularia spp. & $1(1)$ & $1(1)$ & $0(0)$ & $1(1)$ & $3(0.6)$ & - \\
\hline Trichophyton rubrum & $0(0)$ & $1(0)$ & $0(0)$ & $0(0)$ & $1(0.2)$ & - \\
\hline Scopulariopsis spp. & $1(1)$ & $0(0)$ & $0(0)$ & $0(0)$ & $1(0.2)$ & - \\
\hline Acremonium spp. & $0(0)$ & - & $0(0)$ & $1(1)$ & $1(0.2)$ & - \\
\hline Total (\%) & $115(22.3)$ & $170(33)$ & $124(24)$ & $107(20.7)$ & $516(100)$ & $>0.05$ \\
\hline
\end{tabular}

*ANOVA

The mean difference is significant at the 0.05 level

It is in contrast to the study by Rafiei which found that $54.47 \%$ of the total collected samples were positive regarding the fungi elements. However, the corresponding rate of fungal contamination of all collected samples in the present study was more than what had been found in that study. Furthermore, the most common isolates are filamentous fungi in that study which is similar to our results [9].

Compared with the other studies in Iran $[9,17,20]$, the lowest rate of dermatophyte species was isolated in the current study which can be due to the hygiene of the swimmers of our considered pools. In the present study, only one case of Trichophyton rubrum was isolated from foot-washing sink. In addition, in contrast to some previous studies in Iran $[9,11,24]$ and elsewhere $[4,8$, 26], no case of dermatophyte species was isolated from lockers, showers, pool edges, and water, which could be explained by our residual chlorine and isolation method.

In the study of Jankowski in Poland that was done on swimming pools, in contrast to the study, T. mentagrophytes was the most prevalent dermatophyte isolated, while only one species of Microsporum canis was isolated and no case of T. rubrum was isolated, which was detected in $86 \%$ of all adult dermatophytic infections. Also similar to our study, in the study of Jankowski, the most isolated species were Candida spp. [28].

In the study of Brandi in Rome city of Italy, in contrast to other studies, Candida spp. has been never detected, while

Table 4 Mean of physicochemical parameters of swimming pool water according to type of swimming pool and season

\begin{tabular}{|c|c|c|c|c|c|c|c|c|c|c|c|c|}
\hline \multirow{2}{*}{$\begin{array}{l}\text { Physicochemical } \\
\text { parameter }\end{array}$} & \multicolumn{6}{|c|}{ Type of swimming pool } & \multirow[t]{2}{*}{$p$ value* } & \multicolumn{4}{|l|}{ Season } & \multirow[t]{2}{*}{$p$ value ${ }^{*}$} \\
\hline & $\bar{A}$ & $B$ & C & $\mathrm{D}$ & $E$ & $F$ & & Spring & Summer & Fall & Winter & \\
\hline $\mathrm{pH}$ & $7.529 \pm 0.2$ & $7.386 \pm 0.3$ & $7.157 \pm 0.1$ & $7.386 \pm 0.2$ & $7.357 \pm 0.4$ & $7.343 \pm 0.1$ & $>0.05$ & $7.3 \pm 0.2$ & $7.5 \pm 0.2$ & $7.3 \pm 0.2$ & $7.5 \pm 0.2$ & $>0.05$ \\
\hline Residual chlorine & $1.9 \pm 0.7$ & $2.4 \pm 0.5$ & $1.6 \pm 0.6$ & $1.8 \pm 0.3$ & $1.6 \pm 0.4$ & $2.1 \pm 0.6$ & $<0.05$ & $1.8 \pm 0.3$ & $1.8 \pm 0.8$ & $1.8 \pm 0.3$ & $1.8 \pm 0.8$ & $>0.05$ \\
\hline Turbidity & $\begin{array}{l}729.0 \pm \\
101.9\end{array}$ & $\begin{array}{l}802.8 \pm \\
188.2\end{array}$ & $\begin{array}{l}867.1 \pm \\
29.3\end{array}$ & $\begin{array}{l}484.9 \pm \\
261.1\end{array}$ & $\begin{array}{l}833.1 \pm \\
97.7\end{array}$ & $\begin{array}{l}723.0 \pm \\
128.2\end{array}$ & $<0.05$ & $\begin{array}{l}713.7 \pm \\
237\end{array}$ & $\begin{array}{l}721.2 \pm \\
246\end{array}$ & $\begin{array}{l}750.8 \pm \\
208\end{array}$ & $\begin{array}{l}797.8 \pm \\
120\end{array}$ & $>0.05$ \\
\hline Temperature & $29.3 \pm 0.5$ & $29.5 \pm 0.4$ & $29.9 \pm 0.4$ & $29.1 \pm 0.4$ & $29.9 \pm 0.4$ & $29.9 \pm 0.4$ & $<0.05$ & $29.7 \pm 0.5$ & $29.7 \pm 0.5$ & $29.5 \pm 0.5$ & $29.5 \pm 0.5$ & $>0.05$ \\
\hline
\end{tabular}

*ANOVA

The mean difference is significant at the 0.05 level 
similar to the present study, one species T. rubrum was isolated from swimming pools' water and surfaces [26].

Nowadays, diseases caused by free-living amoeba including encephalitis and keratitis are increasing [29]. In our country, various studies have been done on freeliving amoeba in environmental resources including pool water. In the present study, similar to other studies in Iran and the world and in contrast to the study of Armand in Shiraz, one case of Acanthamoeba contamination out of six pools (16.6\%) was isolated. In the present study, Acanthamoeba was isolated in the warm season (summer) of the year where many people are using the pools, which could be the cause of high rates of contamination [30-33].

In a study by Mafi et al. on pool water and pools of amusement parks in Tehran, they reported that the contamination rate with Acanthamoeba was $24 \%$, which is different from the results of our study, due to the low level of contamination in this study that could be due to sampling only from the pool water, while in Mafi et al.'s study, in addition to pool water, samples were collected from the park ponds, due to being in open space and also entering of the dust to these waters which has increased the amount of Acanthamoeba contamination [34].

In a study conducted by Solgi et al. on the hot springs of Ardabil province, 20\% of the hot springs of this province were contaminated with Acanthamoeba parasite. The reason for the difference in the results of our study and that study can be attributed to the difference in water temperature where the water temperature of the hot springs is higher than that of the pool water [35]. The results of the present study indicate that Acanthamoeba free-living amoeba is significantly prevalent in Arak city pools and there is a potential for infection to people who are prone to free-living amoeba.

Our finding showed that the pools' water $\mathrm{pH}$ was between 7.15 and 7.52, which is in accordance with the recommended reference $\mathrm{pH}$ for swimming pool water (7.2-8.0). The pool water $\mathrm{pH}$ in this study in comparison to other studies in Iran was in a better condition. In addition, unlike other studies in Iran $[17,36,37]$, the residual chlorine of all swimming pools was in the standard range $(1-3 \mathrm{mg} / \mathrm{L})$. The water turbidity of the swimming pools in this study was less than 0.5 NTU, which was in the standard condition. In contrast to other physicochemical parameters in the present study and similar to study of Rasti in Kashan [16], the water temperature of swimming pools was more than the standard range $\left(25-29^{\circ} \mathrm{C}\right)$. It is known that high water temperature provides conditions for the growth of pathogenic microorganisms $[35,38]$.

\section{Conclusion and recommendations}

The present study revealed a higher degree of saprophytic fungal contamination of swimming pools with potentially pathogenic Acanthamoeba. Therefore, it is essential to pay closer attention to the hygiene and safety of these swimming pools' water sources.

Based on our findings, the dermatophytic contamination of investigated swimming pools was low and physiochemical parameters except from the water temperature were in the standard range. However, saprophytic fungal contamination of the swimming pools was significant which could be due to the lack of the showering before entering the pool and also to the high temperature of the pool water. Therefore, it is essential to inform the swimmers to improve their knowledge and hygienic behavior.

Acanthamoeba was detected in $16.6 \%$ of the swimming pools, confirming the widespread distribution of these free-living amoeba in the environment and the risks associated with the contamination of contact lens wearers and immunocompromised patients.

Concerning the water contamination of the pools with Acanthamoeba parasite and in order to prevent the occurrence of the corresponding infections, necessary warnings should be made by the health authorities about the precise disinfection of the pools and appropriate strategies for dealing with free-living amoeba should be applied. Moreover, the continuous monitoring of physicochemical parameters especially the residual chlorine and the water temperature is advised to maintain the quality of the pool water.

\section{Acknowledgements \\ We are very grateful to Dr. Mohammad Amin Tabatabaiefar for his helpful consultation and comments on the manuscript.}

\section{Authors' contributions}

This study was done by HS, MD, YH, MG, RH, MK, and RG. HS participated in the design of the study. Data collection was done by $\mathrm{RG}$ and $\mathrm{RH}$.

Interpretation and manuscript preparation were conducted by RG. MG participated in the data editing. MK performed the statistical analysis. MD performed the coordination and helped with the draft of the manuscript. All authors read and approved the final manuscript.

\section{Funding}

The authors gratefully acknowledge the Research Council of Arak University of Medical Science; the project funding number is 916 .

Availability of data and materials

In this study, all data and materials are included. If more information is needed, please contact the author for data requests.

\section{Ethics approval and consent to participate}

The code of ethics of this study is the number 92-147-5. We have obtained approval to conduct our study from the ethics committee of Arak University of Medical Science. This study does not have a participation section as it is not applicable.

\section{Consent for publication}

Not applicable because this manuscript does not contain any individual personal data. 


\section{Competing interests}

The authors declare that they have no competing interests.

\section{Author details}

'Department of Infectious Disease, Arak University of Medical Sciences, Arak, Iran. ${ }^{2}$ Department of Parasitology and Mycology, Arak University of Medical Sciences, Arak, Iran. ${ }^{3}$ Department of Environmental Health Engineering, Arak University of Medical Sciences, Arak, Iran. ${ }^{4}$ School of Paramedical Sciences, Arak University of Medical Sciences, Arak, Iran.

\section{Received: 27 February 2019 Accepted: 23 January 2020} Published online: 17 March 2020

\section{References}

1. Jahanbakhsh HA. Guide to monitoring of swimming pools and coastal water 2013, Tehran. Iran J Public Health. 2004;33(1):60-5.

2. David M. Swimming pool disinfection: techniques and pitfalls. Water Conditioning \& Purification. 2006:1-6.

3. Fournier S, Dubrou S, Liguory O, Gaussin F, Santillana-Hayat M, Sarfati C, et al. Detection of microsporidia, cryptosporidia and giardia in swimming pools: a one-year prospective study. FEMS Immunol Med Microbiol. 2002; 33(3):209-13.

4. Hilmarsdottir I, Haraldsson H, Sigurdardottir A, Sigurgeirsson B. Dermatophytes in a swimming pool facility: difference in dermatophyte load in men's and women's dressing rooms. Acta Derm Venereol. 2005; 85(3):267-8

5. A PCR-Based molecular detection of Strongyloides stercoralis in Human Stool samples from Tabriz City, Iran. Sci Pharm. 2017:85(2):17. https://doi. org/10.3390/scipharm85020017.

6. Boland-Nazar NS, Eslamirad Z, Sarmadian H, Ghasemikhah R. An in vitro evaluation of ozonized organic extra-virgin olive oil on Giardia lamblia cysts. Jundishapur J Microbiol. 2016;9(11):e40839.

7. Didehdar M, Shokohi T, Khansarinejad B, Ali Asghar Sefidgar S, Abastabar M, Haghani I, et al. Characterization of clinically important dermatophytes in North of Iran using PCR-RFLP on ITS region. J Mycol Med. 2016;26(4):345-50.

8. Detandt M, Nolard N. Dermatophytes and swimming pools: seasonal fluctuations. Mycoses. 1988:31(10):495-500.

9. Rafiei A, Amirrajab N. Fungal contamination of indoor public swimming pools, Ahwaz, south-west of Iran. Iran J Public Health. 2010;39(3):124

10. Rabi A, Khader Y, Alkafajei A, Aqoulah AA. Sanitary conditions of public swimming pools in Amman, Jordan. Int J Environ Res Public Health. 2007:4(4):301-6.

11. Nourian AA, Badali $\mathrm{H}$, Hamzehei $\mathrm{H}$. Fungal contamination in indoor swimming pools in Zanjan-Iran 2005. Pak J Biol Sci. 2006:9(13):2524-7.

12. Mikaeili A, Rezaei M. Dermatophytic species isolated in wrestling gyms and swimming pools of Kremanshah, Iran. Med Lab J. 2008:2(1):37-40.

13. Trabelsi H, Dendana F, Sellami A, Sellami H, Cheikhrouhou F, Neji S. Pathogenic free-living amoebae: epidemiology and clinical review. Pathol Biol. 2012;60(6):399-405

14. Bunting L, Neilson JB, Bulmer G. Cryptococcus neoformans: gastronomic delight of a soil ameba. Sabouraudia. 1979;17(3):225-32.

15. Ramirez E, Campoy E, Matuz D, Robles E. Acanthamoeba isolated from contaminated groundwater. J Eukaryot Microbiol. 2006;53(S1):10-1.

16. Hoseinzadeh E, Mohammady F, Shokouhi R, Ghiasian SA, Roshanaie G, Toolabi $A$, et al. Evaluation of biological and physico-chemical quality of public swimming pools, Hamadan (Iran). Int J Environ Health Eng. 2013;2(1):21.

17. Rasti S, Asadi MA, Iranshahi L, Hooshyar H, Gilasi HR, Zahiri A. Evaluation of parasitic and fungal contamination and physicochemical parameters of indoor public swimming pools in Kashan during 2008-9. Feyz, Journal of Kashan University of Medical Sciences. 2010;15(1):77-83.

18. Krejcie RV, Morgan D. Determining sample size for research activities. Educ PsycholMeas. 1970;30(3):607-10

19. Rippon JW, editor. The pathogenic fungi and the pathogenic actinomycetes. In: Medical mycology. 3rd ed. Philadelphia: W.B. Saunders Co. $1988 ;$ p. 570

20. Hasanvand S, Azadegan Qomi H, Kord M, Didehdar M. Molecular epidemiology and in vitro antifungal susceptibility of Candida isolates from women with vulvovaginal candidiasis in northern cities of Khuzestan Province, Iran. Jundishapur J Microbiol. 2017;10(8):e12804.

21. Vesaluoma M, Kalso S, Jokipii L, Warhurst D, Ponka A, Tervo T. Microbiological quality in Finnish public swimming pools and whirlpools with special reference to free living amoebae: a risk factor for contact lens wearers? Br J Ophthalmol. 1995:79(2):178-81.

22. Shadzi SH, Pour MH, Zare A, ChadeganiPour M. Fungal contaminations in four swimming pools in Isfahan, Iran. Iran J Basic Med Sci. 2001:4(1):9-12.

23. Shadzi SH, Pour MH, Zare A, Chadeganipour M. Fungal contaminations in four swimming pools in Isfahan, Iran; 2001.

24. Jafari AA, Ghaneian MT, Ehrampoush MH, Zarei S. Survey of fungal contamination in surfaces of Yazd indoor swimming pools in 2011. Toloo-ebehdasht. 2013:12(2):61-9.

25. Papadopoulou C, Economou V, Sakkas H, Gousia P, Giannakopoulos X, Dontorou C. Microbiological quality of indoor and outdoor swimming pools in Greece: investigation of the antibiotic resistance of the bacterial isolates. Int J Hyg Environ Health. 2008;211(3):385-97.

26. Brandi G, Sisti M, Paparini A, Gianfranceschi G, Schiavano GF, De Santi M, et al. Swimming pools and fungi: an environmental epidemiology survey in Italian indoor swimming facilities. Int J Environ Health Res. 2007;17(3):197-206.

27. Viegas C, Alves C, Carolino E, Pinheiro C, Rosado L, Santos CS. Assessment of fungal contamination in a group of Lisbon's gymnasiums with a swimming pool. J Occup Environ Hyg. 2011;2(1):15-20.

28. Jankowski M, Charemska A, Czajkowski R. Swimming pools and fungi: an epidemiology survey in Polish indoor swimming facilities. Mycoses. 2017; 60(11):736-8.

29. Lorenzo-Morales J, Monteverde-Miranda CA, Jiménez C, Tejedor ML, Valladares B, Ortega-Rivas A. Evaluation of Acanthamoeba isolates from environmental sources in Tenerife, Canary Islands, Spain. Ann Agric Environ Med. 2005:12(2):233-6.

30. Poor BM, Dalimi A, Ghafarifar F, Khoshzaban F, Abdolalizadeh J. Contamination of swimming pools and hot tubs biofilms with Acanthamoeba. Acta Parasitol. 2018;63(1):147-53.

31. Caumo K, Frasson AP, Pens CJ, Panatieri LF, Frazzon AP, Rott MB. Potentially pathogenic Acanthamoeba in swimming pools: a survey in the southern Brazilian city of Porto Alegre. Ann Trop Med Parasit. 2009;103(6):477-85.

32. Rahdar M, Niyyati M, Salehi M, Feghhi M, Makvandi M, Pourmehdi M, et al. Isolation and genotyping of Acanthamoeba strains from environmental sources in Ahvaz city, Khuzestan province, southern Iran. Iran J Parasitol. 2012;7(4):22-6.

33. Armand $\mathrm{B}$, Motazedian $\mathrm{MH}$, Asgari $\mathrm{Q}$. Isolation and identification of pathogenic free-living amoeba from surface and tap water of Shiraz City using morphological and molecular methods. Parasitol Res. 2016;115(1):63-8.

34. Mafi M, Niyyati M, Haghighi A, Lasjerdi Z. Contamination of swimming pools and park ponds with free living amoebae in Tehran. Med J Tabriz Univ Med Sci Health Serv. 2017:38(6):60-7.

35. Solgi R, Niyyati M, Haghighi A, Taghipour N, Tabaei SJS, Eftekhar M. Thermotolerant Acanthamoeba spp. isolated from therapeutic hot springs in northwestern Iran. J Water Health. 2012;10(4):650-6.

36. Fadaei A, Amiri M. Comparison of chemical, biological and physical quality assessment of indoor swimming pools in Shahrekord city, Iran in 2013. Global J Health Sci. 2015:7(3):240.

37. Neghab M, Gorji A, Baghapour M, Rajaeifard A. A study of Shiraz swimming pools contamination. SJKUMS. 2004;7(3):41-9.

38. Maida CM, Di Benedetto MA, Firenze A, Calamusa G, Di Piazza F, Milici ME, et al. Surveillance of the sanitary conditions of a public swimming pool in the city of Palermo (Italy). Ig Sanita Pubbl. 2007;64(5):581-93.

\section{Publisher's Note}

Springer Nature remains neutral with regard to jurisdictional claims in published maps and institutional affiliations. 